want of phosphatic salts in the organism. He combineed with this treatment a diet which was rich in phosphates.

Professor Kraske (Freiburg), who followed Kocher, said his experience was limited to 425 cases, and he had had a deathrate of 5 per cent.

Dr. Goldmann related a case of intrathoracic goître which proved to be formed of masses of carcinomatous tissue undergoing tuberculous degeneration.

Dr. Riedel suggested that the presence of the neighbouring organs forced the left side of the enlarged gland downwards into the thorax, while the right side was displaced upwards toward the lobe of the ear. In operating, he believed that it was advisable to tie the veins first, before the extirpation was undertaken.

Herr König said that goîtres were observed in flat as well as mountainous districts, and it was a curious fact that, out of 80 cases which he had'seen in Berlin, about one-half occurred in natives of the city.

SURGERY OF THE Brain.

Professor Krause (Berlin) reported 27 cases in which he operated for the relief of severe neuralgic pains of the head. Two cases ended fatally, while relief followed the rest of the operations. He was able to say that the relief was lasting, as he had followed up the cases for a time varying between five and a-half and eight and a-half years. He described the technique of his operation for the removal of the Gasserian ganglion.

Dr. Heidenhain (Worms) related 4 cases of cerebral tumours which he had removed by operation. In one case he found a cystic sarcoma in the right motor area, which he succeeded in removing, and effected a lasting cure.

Dr. Barth (Danzig) showed a boy who had received a stab in the back, which pierced the spinal canal, and led to suppuration. After a time symptoms of severe disturbance inside the spinal canal manifested themselves in the shape of opisthotonos, fever, etc. Lumbar puncture was made, and some purulent fluid was withdrawn. A laminectomy was therefore undertaken, and, with suitable local treatment led to a complete recovery.

Herr Krönlein (Zurich) reported a case of Jacksonian epilepsy for which he had operated. He made the diagnosis of the localisation of the growth, but failed on trephining to detect any pathological abnormality. The patient died a year and a-half later, and at the necropsy a large circumscribed spindlecell sarcoma situated at the same spot where he had sought the tumour, was found. He concluded that the growth was too deep-seated and small at the time of the operation for him to discover. The specimen was handed round.

Dr. Merkens (Berlin) spoke of encephalitis and temporosphenoidal abscess following otitis media.

Dr. Tilmans (Greifswald) gave the results of his experiments on animals in connection with intracranial pressure.

Dr. Braun (Göttingen) had tried the removal of the cervical sympathetic ganglia for epilepsy in 9 cases, but did not agree with Jonnesco that it was of use. As far as the operation itself was concerned it was not dangerous if carefully performed. He preferred to make his incision posteriorly. The contraction of the pupils and changes in the discs which appeared after the removal of the ganglia soon disappeared, but the ptosis re mained. None of his cases showed any detinite improvement.

Gunshot Wounds.

Dr. Schjering (Berlin) gave an interesting address on wounds caused by modern firearms. He dealt first with wounds caused by shells. The size of the bone splinters, the relative magnitude of the entrance and exit wounds, and the general effects on limbs, head, etc., were well exemplified not only by the description, but also by a large number of Roentgen-ray and other photographs. He spoke at some length on the interest which abdominal gunshot wounds '(shell and small-arm projectiles) called forth in surgery. That modern bullets were less likely to prove fatal than ancient ones, and that modern surgical methods were so much in advance of the older methods, was shown by the fact that so many of the wounded who could be removed alive from the battlefield into hospital eventually recovered. He concluded by saying that one might look with confiaence to the future, believing that the military surgeon's work would be crowned with success.

Professor Krönlein (Zurich) showed three bullets which had been, by some unknown means, pierced at right angles by another bullet.

Dr. Ringer (Hamburg) and Dr. Tilman spoke of their experiences of the South African war. The former directed his attention chiefly to the wounds affecting blood vessels and nerves.

Dr. Ziemssen (Wiesbaden) related his experiences with the after-treatment of the wounded and invalided in watering places, and expressed the wish that such places could be managed on surgical principles.

\section{Sirgery OF The Testis.}

Professors von Bruns and von Baumgarten (Tübingen) each read a paper dealing with the question of castration for tuberculous disease of the testis. The former approached the subject from the standpoint of practical surgery, and reported, out of his experience during the past fiity years, that with one-sided castration he could show a lasting cure in 46 per cent., while with double castration he cured 57 per cent. He lost 12 per cent. of all his cases. The psychological changes which were said to follow double castration were not noted. With regard to a large number of cases, he called attention to the fact that the presence of tuberculous lesions in other parts of the body greatly lessened the chances of recovery, and that this condition was unfortunately by no means rare.

The second speaker controlled the clinical conclusions by laboratory experiments, chiefly on rabbits. He found that by injecting the genital canal from the urethra, he could only with difficulty succeed in reaching the sexual glands. On the other hand, he found that the infection could travel easily in the reverse direction. The opposite side was never infected directly from the experimented side. He stated that bacillary growth always took place in the direction of the stream of lymph, blood, or secretion. Unlike the gonococcus, the tubercle bacillus never multiplied in the secretory fluid.

\section{AN ARMY MEDICAL SCHOOL IN LONDON.} By G. H. Makins, F.R.C.S., Surgeon to St. Thomas's Hospital. London; lately Consulting Surgeon

While discussion is proceeding as to the possibility of improvements in the Royal Army Medical Corps, it may not be inopportune to reopen the consideration of two suggestions already made on more than one occasion. These consist in the establishment of a large military hospital in London, and the transference of the Army Medical School into direct connection with it. The combined institution would at the same time be brought into immediate association with the headquarters of the corps.

Two main difficulties exist in the maintenance of the corps at the level of first-rate efflciency: (1) The small number of young medical men at present willing to enter its ranks. (2) The small opportunities which exist for a large number of those in the corps to keep themselves thoroughly abreast of the continuous advances made in practical medicine and surgery.

The explanation of the small number of men entering the service may be first considered. This is no doubt influenced by the comparatively small number of individuals entering the profession at all at the present time. This deficiency, partly due to the elongation of the medical curriculum and the consequent increase in the expense of obtaining a diploma partly a result of the satisfactory state of trade and other professions during the last decade, has been felt much more widely than in the Royal Army Medical Corps alone; thus country house-surgeoncies, posts as assistants, etc., have been and are increasingly difficult to fill up. Although a temporary difficulty, since no doubt the pendulum will swing over with an increasing demand, this cause may be expected to affect the number of applicants for commissions in the service for some time to come, and is a strong reason for special efforts on the part of the War Department to obtain officers.

Beyond this general deficiency in supply of medical men 
certain conditions of the service itself render it unpopular with young medical men. These may be shortly summarised as follows: The necessity of submission to discipline, renunciation of the exercise of sole responsibility so characteristic of the medical profession, want of scope for practical work, a definite limitation of the income to be earned, the practical necessity of celibacy during the early period of service, with the consequent impossibility of settling into a home, and lastly, promotion by seniority. As these objections to the service are insuperable, they can only be compared with the advantages recounted in the succeeding paragraph. With regard to the last-mentioned, however, perhaps more is made of it than it deserves. The promotion of every member of the staff of a civil hospital stands on exactly the same basis, and in common fairness seniority must always remain the main element in promotion among every body of men, cases of manifest inefficiency or unsuitability apart.

Certain material advantages offered by the service as a oareer are, on the other hand, at once apparent. A good social position is attained at a step, also a certain means of livelihood with an assured pension. Opportunity is open for travel, and for the observation of many forms of disease which do not occur in ordinary practice. Again, the discipline which frepels some is welcomed by certain temperaments, to many the military atmosphere is agreeable. In these respects the army offers an inviting prospect to many men of obvious powers, to whom the often weary round of private practice is distasteful.

Secondly, as to the difficulty in maintaining practical medical knowledge, this might be materially lessened were the army possessed of more modern and efficiently equipped military hospitals. The first step in ensuring this should be the establishment of a commodious and in all respects firstclass hospital in connection with the Army Medical School in London.

This effected, it appears reasonable to expect that the following advantages to the service might result :

The hospital in London would of necessity be kept up to a state of efficiency corresponding with that of the best of the civil general hospitals which would surround it. As possess. ing such qualifications it would serve as a model for the numerous military hospitals throughout the ceuntry, and tend to raise their efficiency also.

It would afford opportunity for a number of the members of the service to be passed through its appointments, and thus ensure among them a familiarity with the most modern methods. Beyond the practice afforded by the hospital itself, the situation in London would allow the officers for the time being attached to thoroughly familiarise themselves with the work of the surrounding hospitals and medical schools.

A number of officers of the rank of major could be passed through annually in the position of hospital physicians and surgeons, while at the head of the medical and surgical departments consulting officers, probably the professors of military medicine and surgery, would hold office for a longer period.

In association with each major a surgeon-lieutenant might hold office as house-surgeon or physician, and in this way the service would turn out from its own hospital a considerable number of men who had held an office of this character.

The difficulty may be raised as to the means of 'supply of patients to such a hospital. This could scarcely prove insuperable. A nucleus exists in the patients already treated in the military hospitals in London, and this might be increased by drafting serious cases from the country hospitals to the headquarters in London. A further large supply could at once be tapped if the men at present refused by the recruiting officers, instead of being sent to the general hospitals for operations necessary before they could be enlisted, were treated in a military hospital at the expense of the Government, as they should be. The present hospital at Netley, besides acting as a receiving depôt, would furnish the hospital in London with that invaluable adjunct--a convalescent department.

A sufficient number of cases would also be obtainable for the establishment and maintenance of various special departments.

Additional facilities would be afforded for the training of nurses on the special lines necessitated by military service.

The immediate proximity of the headquarters of professional work to that of the corps would be a material advantage. The Director-General would have opportunity of becoming personally acquainted with the work of many officers in the service, as to which at the present time he has to be satisfied with the reports of others.

Although the impossibility of any system of specialisation in the service is obvious, yet the working of such a hospital at headquarters would allow of the authorities becoming well acquainted with the special bent and powers of the medical officers, and this might be of very material help in the filling up of appointments either of a medical, surgical, or any special nature.

As to the general advantage of the association of the Army Medical School with the hospital no doubt can exist, since although the connection could not bring the same advantages in the way of students, the opportunities for work on the part of those engaged in the hospital would be manifestly increased and improved. In point of fact the hospital alone could scarcely afford sufficient duty for its staff without some such arrangement, unless the staff was so limited as to render the first object of the scheme nugatory.

Lastly, how might this arrangement be expected to influence the entry of men into the service? First of all, as an obvious centre, it would bring the service and its work much more prominently under the notice of a large body of medical students, and as doing this would tend to familiarise it. Beyond this, however, the school should be made an active influence, and an important factor in the entry of future officers.

In the German system the State takes an active part in the preparation of students for the medical department of the army, subsidising the education of such officers, and in some measure regulating the curriculum through which they pass in order to ensure their suitability for the duties they will have to fulfil.

In this way the students become thoroughly acquainted with their future work, and the discipline to which they will be subjected, at a considerably earlier and more favourable period than is the case in our own service. Some move in the same direction would probably prove an advantage.

It is unlikely that any advantage could be gained by the Army Medical School actually undertaking the education of students before the period of qualification, yet in place of the system of subsidisation employed in Germany it might be suggested that the Government should attempt to increase the supply of candidates, and attach them at an earlier date by a system of scholarships in the various medical schools offered at the end of the fourth year's work-these scholarships to carry free education during the fifth year, the men joining the Army Medical School on obtaining their qualification, and then undergoing a similar course of training to that at present given at Netley. At the termination of this course the examination for commissions would be held, under the much more favourable conditions of a full knowledge of the personal qualifications of the candidates on the part of the service. Although this plan would entail some cost to the Government in respect to those candidates who were found unsuitable for the service, none the less a great advantage would be gained in the selection of really suitable men.

'To the candidates, no loss of time would result, even if they failed to secure a commission; while on the part of the Government a saving clause might be inserted, making the payment of the fifth year's fees dependent on the candidate obtaining a legal qualification within a definite period.

The creation of such a class of students, beyond-offering the above advantages in the future choice of officers, would probably very materially increase the number of candidates, not only by reason of the monetary advantage offered, but also by familiarising students with the service at a much earlier date.

In the case of students of superior attainments likely to hold the junior house offices at their hospitals, some arrangement could no douht be made without sacrifice of seniority on the part of the men concerned. It sometimes happens at the present time that men abandon their chance of holding 
an appointment that would be invaluable to them in afterpractice, in order to ensure six or nine months' seniority in the service. Although this is uncommon, no chance should be allowed for its occurrence. The time spent in a house appointment by a medical military cadet might be allowed to count as a similar period passed as a surgeon-lieutenant holding a similar office in the military hospital.

IMPERIAL YEOMANRY HOSPITAL, DEELFONTEIN.

DR. J. HALL-EDwards, Surgeon-Radiographer and Staft Officer to this hospital, has sent us under date March gth the following notes :

Shortly before the close of 1900 our accommodation was considerably reduced by sending up country a number of marquees which had been placed at our disposal by the Gove: 1 ment. Even now, however, we have a larger number of beds than it was the original intention of the Committee to supply, and were it not that a large number of our patients are convalescents, it would be impossible for our small staff to keep pace with the work.

For about two months prior to the invasion of Cape Colony our hospital contained so few acute cases, that to all intents and purposes it was little more than a rest camp for convalescents. Since January ist, however, our work has gradually increased, until at the present time we have as much work as we have ever had with the same number of beds. At the present time our staff consists only of six medical officers, and our commandant (Colonel Sloggett). We have in hospital 587 patients, 170 of which are acute cases, including 48 cases of enteric fever. On the surgical side our rrork has of late much increased, and twice during the last fortnight we have, for the first time in the hospital, received wounded men straight from the field.

For the last three weeks intelligence wires and scouts have cegularly arrived, telling us of the presence of Boers in our immediate neighbourhood. Last week a scout was fired at from a kopje only two miles distant from the camp, and one night a Kaffir kraal less than a mile away was visited by six Boers, who questioned the natives about the hospital. They were anxious to know how many rifles we had in stores, the number of our horses, and the strength of the guard at the railway station. On hearing of this our store of rifles and ammunition was despatched to De Aar, and orders were issued prohibiting any of the staff from riding more than a mile from the hospital.

At midnight on February 26th an urgent message was received from the General in command at De Aar, asking us to send at once to Richmond Road Station a surgeon and men to bring in 20 wounded men of Kitchener's Fighting scouts. Luckily, a train was held up for the night at the station, and the engine, a truck, and the guard's van were placed at our disposal, and Mr. Parker (our senior surgeon) and eight men, with bedding, stretchers, rations, medical comforts, dressings, etc., started at I.15 A.n. It appears that a patrol of 60 of Kitchener's Fighting scouts had fallen in with 200 of the enemy under Malan. Five men were killed in action, 7 were wounded, and the remainder were taken prisoners, but were released after handing over their horses, arms, and ammunition. The fight took place at Klip Kraal, 18 miles distant from Richmond Road Station.

Mr. Parker at once made arrangements to proceed to the scene of action. The only available velhicle for bringing in wounded was a bullock waggon, which could not start until daylight. Mr. Parker, an orderly, and driver started in a Cape cart, leaving the remaining orderlies and waggon to follow as soon as possible. Owing to the recent heavy rains, the occupants of the Cape cart had rather an adventurous journey, which ended in their having to swim a river. At ro.30 P.M. February 27th, Mr. Parker arrived at Deelfontein bringing with him two seriously wounded officers and one man. Three other cases were left with the orderlies, under the care of a medical man from Victoria West, to come on by the next train. I am sorry to say that one of the officers died of his wounds on the third day after his arrival here and one of the privates (shot through the spine) who was left to come with the second lot, died before arrangements could be made for his removal from the farmhouse, where he had been carried from the field. The other patients are all doing well.
In addition to the usual number of patients received from up country, we are now daily taking in a large number from the south, generally acute cases which come straight from the columns operating south of us. Most of the fighting down country has taken place between here and a distance of 70 miles. As the nearest base hospital to us is at Capetown, a distance of 470 miles, and as no trains are allowed to run at night between Beaufort West and here, it is much more convenient, and occupies much less time, to send the patients here than to despatch them to Capetown. On March 6th an officer, three men, and a Kaffir were sent in wounded from Modderfontein, where a small fight had taken place between the Bedfords and the scouts of Malan's commando. In one case a bullet had passed through the frontal bone, and the man died.

At the present time we have more gunshot wounds in hospital than we have ever had. During the last fortnight three bullets (which had been previously localised by means of the $x$ rays) have been successfully removed, bringing the total number of bullets, portions of bullets, and pieces of shell, removed here since the establishment of the hospital up to 70. Not a bad record, taking into consideration the fact that up to quite recently we have received no cases straight from the field.

Enteric fever is not nearly so bad as it has been, although some of the cases are very severe. The following list shows the number of cases of enteric fever which have been in hospital since February ist:

February rst

$" \quad 8$ th

$34 \quad$ February 22nd $\quad \ldots$

52
34
48

Between February 22nd and March ist a hospital train was placed at our disposal, in which we despatched to the base a number of cases which had not reached the convalescent stage. This step was necessary owing to the hospital being full, and in order to comply with the Principal Medical Officer's orders that we should keep a number of beds empty ready to receive wounded men.

The enteric cases are under the care of Dr. Eliot, our chief C.M.O., and Dr. Snowden. Dr. Richmond has the care of the acute dysenteric ward. The surgical cases are under the care of $\mathrm{Mr}$. Parker and Mr. Caddick; whilst I, in addition to $\mathrm{my}$ special work, act as staff officer and look after a convalescent ward.

The close proximity of the enemy has bothered us very little, and the work has gone on as usual. Almost every day we get a scare, but we are getting so used to them that (having made all preparations) we feel rather slighted that a visit has not been paid to us. Our equanimity, however, has been slightly upset by the statement which appears on p. 37 of the Report of the Hospital Commission, namely, "It should be remembered that fixed hospitals are not exempt from capture under the Geneva Convention." Before reading this we were under the false conviction that we were quite safe; now, however, we have our doubts.

On March 3 ist our hospital is to be handed over to the R.A.M.C., when it will be run as a convalescent camp. How this is going to be managed under present conditions is difficult to understand, for unless very different arrangements are made it is absolutely necessary that a general hospital should be provided somewhere in this district.

\section{THE PREVENTION OF TUBERCULOSIS.}

Tuberculosis Conference in Canada.

A Conference on Tuberculosis was held at Ottawa on February isth on the call of the Earl of Minto, the GovernorGeneral, and the Countess of Minto. There was a large attendance of influential members of the medical profession and of leading citizens of the Dominion.

The Prevalence of Tuberculosis in Canada.

The Governor-General, who presided, delivered an address in which he recalled the fact that during the meeting of the Canadian Medical Association held at Ottawa in September, 1900, an Association for the Prevention of Tuberculnsis was provisionally organised. He had asked them to assemble in order to establish that Association on a permanent basis, and to discuss the measures best calculated to promote the ob- 